\title{
Screening of inbred popcorn lines for tolerance to low phosphorus
}

\author{
O.J.A.P. Santos ${ }^{1}$, L.S.A. Gonçalves ${ }^{1}$, C.A. Scapim ${ }^{2}$, de S.M. de Sousa ${ }^{3}$, \\ C.R. Castro ${ }^{2}$, V. Y. Baba ${ }^{1}$ and A.L.M. de Oliveira ${ }^{1}$ \\ ${ }^{1}$ Universidade Estadual de Londrina, Londrina, PR, Brasil \\ ${ }^{2}$ Universidade Estadual de Maringá, Maringá, PR, Brasil \\ ${ }^{3}$ Embrapa Milho e Sorgo, Sete Lagoas, MG, Brasil \\ Corresponding authors: O.J.A.P. Santos / L.S.A. Gonçalves \\ E-mail: odairjap@gmail.com / leandrosag@uel.br
}

Genet. Mol. Res. 15 (2): gmr.15027519

Received August 25, 2015

Accepted November 19, 2015

Published May 6, 2016

DOI http://dx.doi.org/10.4238/gmr.15027519

\begin{abstract}
Increasing phosphorus use efficiency in agriculture is essential for sustainable food production. Thus, the aims of this study were: i) to identify phosphorus use efficiency (PUE) in popcorn lines during the early plant stages, ii) to study the relationship between traits correlated with PUE, and iii) to analyze genetic diversity among lines. To accomplish this, 35 popcorn lines from Universidade Estadual de Maringá breeding program were studied. The experiment was conducted in a growth chamber using a nutrient solution containing two concentrations of phosphorus (P): $2.5 \mu \mathrm{M}$ or low P (LP) and $250 \mu \mathrm{M}$ or high $\mathrm{P}$ (HP). After 13 days in the nutrient solution, root morphology traits, shoot and root dry weight, and P content of the maize seedlings were measured. A deviance analysis showed there was a high level of genetic variability. An unweighted pair group method with arithmetic mean (UPGMA) clustering analysis identified three groups for the LP treatment (efficient, intermediate, and inefficient) and three groups for the HP treatment (responsive, moderately responsive,
\end{abstract}


and unresponsive). The results of a principal component analysis and selection index were consistent with the UPGMA analysis, and lines 1, $2,13,17,26$, and 31 were classified as PUE.

Key words: Zea mays var. everta; Abiotic stress; Root and shoot traits; WinRHIZO

\section{INTRODUCTION}

Popcorn (Zea mays var. everta) is a popular snack food among Brazilians and can be found across the country in a wide range of establishments in the food industry (Amaral Jr et al., 2013; Gonçalves et al., 2014). The economic importance of popcorn has resulted in continued yearly growth due to its higher aggregate value compared with corn and other annual crops such as soybean, especially for small holder farmers (Moterle et al., 2012).

Abiotic stresses represent a major barrier for popcorn cultivation and include water, temperature, salinity, and nutrient deficiencies in tropical and subtropical soils. Of these, phosphorus $(\mathrm{P})$ deficiency is considered to be a major constraint for crop production (LópezArredondo et al., 2014) and represents the macroelement that is available in the lowest amount to plants (Hammond et al., 2004; Bennetzen and Hake, 2009). Phosphorus (P) is an essential element and a primary constituent of organic molecules such as nucleic acids and ATP, which constitute DNA and active transport in living cells (Schachtman et al., 1998; Suh and Yee, 2011).

Retention in labile or stable forms occurs when P precipitates in a solution with ionic forms of calcium, iron, and aluminum, and especially by adsorption to the surface of iron and aluminum oxides, hydroxides, and oxy-hydroxides, which are present in high quantities in weathered soils (Calderón-Vázquez et al., 2011).

The most common management practice to minimize P deficiency is the utilization of phosphate fertilizers that are predominately derived from phosphate-containing rocks. Phosphate fertilizers have been widely used in agriculture, and have significantly contributed to food production and security (Richardson et al., 2011; Veneklaas et al., 2012); however, recent estimates indicate that prices will increase in the coming decades, and that phosphate reserves may be depleted in this century (Cordell et al., 2009; Scholz et al., 2013).

Therefore, increasing P use efficiency (PUE) in agriculture is essential to sustain food production (Elser, 2012; Rose et al., 2013). The two components of PUE are P acquisition efficiency (PAE) and P internal utilization efficiency (PUTIL) (Moll et al., 1982). Parentoni and Souza Júnior (2008) showed that both efficiency indexes should be considered in breeding programs, but the higher importance of PAE compared to PUTIL should be taken into account when establishing selection indexes for these traits as tropical maize plants are grown in high (HP) and low P (LP) soils. Morphological, physiological, and/or biochemical aspects from the plant root system, such as root architecture, microorganism interactions (mycorrhizae and bacteria), and exudate production of organic anions and phosphatase enzymes contribute to PAE (Wang et al., 2010). Conversely, PUTIL is mainly attributed to the recycle, transport, and use efficiency of P stored in the plant under conditions of low P availability (CalderónVázquez et al., 2011; Veneklaas et al., 2012).

Differences between genotypes that efficiently use P can be observed in the early plant stages, and these plants exhibit shoot reduction, and changes in root growth and architecture in LP environments (Bayuelo-Jiménez et al., 2011; de Sousa et al., 2012). Thus, early selection 
for P efficiency is essential to accelerate breeding programs once it allows quick selection in a controlled environment, especially when field experiments are more expensive and cannot always be performed due to climatic conditions (Mundim et al., 2013; Zhang et al., 2014).

The use of adequate phenotyping methods to analyze seedling roots may reduce costs and time, which would allow breeders to focus their field studies on promising lines (Zhu and Lynch, 2004; Walker et al., 2011; Lynch and Brown, 2012; Kumar et al., 2012). Therefore, the aims of this study were as follows: i) to identify PUE lines in early plant stages, ii) to study the relationship between variables correlated with PUE, and iii) to analyze the genetic diversity between lines.

\section{MATERIAL AND METHODS}

A total of 35 popcorn plant lines from Universidade Estadual de Maringá breeding program, which is located in Maringá, Brazil, were analyzed. The experiment was performed in a growth chamber with an average daily temperature of $27^{\circ} \pm 3^{\circ} \mathrm{C}$, night temperature of $20^{\circ} \pm 3^{\circ} \mathrm{C}$, and light intensity of $330 \mu \mathrm{mol}$ photons $\cdot \mathrm{m}^{-2} \cdot \mathrm{s}^{-1}$, with a photoperiod of $12 \mathrm{~h}$ and continuous aeration.

The seeds were disinfected with $0.5 \%$ sodium hypochlorite for $5 \mathrm{~min}$, washed in deionized distilled water, and then germinated on moistened germination paper rolls. After germination for 4 days, the endosperm was removed from the seeds to eliminate the nutritional reserves, especially P (Rose et al., 2013), and three uniform seedlings were selected for each of the three replicates. The experimental design was completely randomized, with three replicates, and two treatments: LP and HP at 2.5 and $250 \mu \mathrm{M}$ P, respectively, in a modified Magnavaca nutrient solution (Magnavaca et al., 1987). A system consisting of plastic file folders lined with germination paper was used for hydroponic growth (de Sousa et al., 2012). The nutrient solution was replaced every 3 days, and the maize seedlings were analyzed 13 days after they were transferred to the paper pouches.

Root images were captured using a digital photography setup and analyzed using the RootReader2D (http://www.plantmineralnutrition.net/rr2d.php) and the WinRHIZO (http:// www.regent.qc.ca/assets/winrhizo_about.html) software according to de Sousa et al. (2012). The following traits were analyzed: total root length $(\mathrm{RL})(\mathrm{cm})$, total root surface area $(\mathrm{RSA})$ $\left(\mathrm{cm}^{2}\right)$, total root volume $(\mathrm{RV})\left(\mathrm{cm}^{3}\right)$, length of fine roots $(0.0<\mathrm{d} \leq 1.0)(\mathrm{RL} 1)(\mathrm{cm})$, and surface area of fine roots $(0.0<\mathrm{d} \leq 1.0)(\mathrm{RSA} 1)\left(\mathrm{cm}^{2}\right)$. After image acquisition, the seedling roots and shoots were each dried to a constant weight at $65^{\circ} \mathrm{C}$ in order to obtain shoot dry weight (SDW), root dry weight (RDW), and total dry weight (TDW). The shoot P content (SPC) and root P content (RPC) were measured by the blue molybdenum spectrophotometry method (Pradhan and Pokhrel, 2013; Santos et al., 2014).

Genetic statistical analyses were performed using the Selegen-REML/BLUP (restricted maximum likelihood/best linear unbiased prediction) software (Resende, 2007), model 83 (completely randomized, unrelated clones tested, and one plant per plot or plot average used) represented in matrix form by:

$$
\mathrm{y}=\mathrm{Xu}+\mathrm{Zg}+\mathcal{E}
$$

where $y$ is the vector of observed and known data, is the scalar for the overall mean (fixed effect), is the vector of genotypic effects (assumed to be random), is the error or residual 
vector (random), and $X$ and $Z$ are the matrices for specific effects. Deviances were calculated for each variable, and their significance was tested by the chi-square test at a 5\% probability level. Values for heritability, experimental coefficient of variation, and predicted means were calculated.

The Pearson correlation coefficient was calculated for the predicted means, and unweighted pair group method with arithmetic mean (UPGMA) hierarchical clustering using standard Euclidean distances, and a principal component analysis (PCA) were used for the genetic diversity analyses, which were performed using the R software program (http//www.r-project.org).

Lines were selected using the selection index in LP conditions, which calculates the distance of each line to an ideal genotype. To calculate this index, the variables were standardized, and then the ideal genotype was defined as a line with the largest values for the variables R1DL, SDW, RDW, SPC, and RPC. Next, the Euclidean distances between each line and this ideal genotype were calculated using the formula:

$$
d_{j I}=\sqrt{\sum\left(X_{i j}-X_{I i}\right)^{2}}
$$

where $d_{j I}$ is the Euclidean distance between line $j$ and the ideal genotype $I, X i j$ is the average of trait $i$ in line $j$, and $X_{\mathrm{Ij}}$ is the value defined by the ideal genotype $I$ for trait $i$.

\section{RESULTS}

The deviance values, which differed significantly by the chi-square test at $5 \%$ probability for all of the variables analyzed at LP and HP, indicate high genetic variability between the tested popcorn lines (Table 1). The estimated heritability values were low for RV ( 0.12 for LP and 0.32 and HP) and RPC ( 0.27 for LP), whereas those for the other variables were medium-to-high and ranged from 0.42 (RSA) to 0.56 (SDW and TDW) for LP, and 0.61 (RDW) to 0.75 (DG) for HP.

According to the coefficient of variance $(\mathrm{CVe})$, the experiment was more precise under conditions of high $\mathrm{HP}$, which presented values ranging from 10.13 to $32.43 \%$, compared with LP, which presented values ranging from 15.00 to $54.59 \%$. Pearson correlation analysis revealed a significant correlation among all traits in both the LP and HP conditions (Table 2). However, the RPC and SPC did not show a significant correlation with root morphology traits, but did with low root P content and TDW under low P. However, under HP, the SPC was correlated with the other analyzed traits, whereas the root $\mathrm{P}$ content was only correlated with RDW and TDW.

Using average standardized Euclidean distances, UPGMA clustering analysis generated three clusters based on the phenology and physiology of the plants under LP (Figure 1). The first group contained six lines (Pop 26, 31, 17, 13, 01, and 02) that presented the highest values for most traits, so they were classified as $\mathrm{P}$ use efficient. The second group contained nine lines (Pop 30, 34, 27, 29, 14, 21, 28, 32, and 33) that presented high values for RSA, RV, and RDW, intermediate values for R1DL, R1DSA, SDW, and TDW, and low values for DG and RPC, and these were classified as moderately $\mathrm{P}$ efficient. The third group contained the remaining lines that presented low values for most traits and was classified as P inefficient. 
Table 1. Variance components and broad-sense heritability $\left(\mathrm{h}^{2}\right)$ estimates, means, and coefficients of variation $(\mathrm{CVe}, \%)$ for 10 traits related to phosphorus (P) use efficiency evaluated in 35 inbred popcorn lines and two inbred maize lines (controls) under two P levels.

\begin{tabular}{l|c|c|c|c|c|c|c|c}
\hline \multirow{2}{*}{ Traits $^{\mathrm{a}}$} & \multicolumn{9}{|c}{ Low P (LP) } & \multicolumn{4}{c}{ High P (HP) } \\
\cline { 2 - 9 } & Deviance & $\mathrm{h}^{2}$ & Mean & CVe(\%) & Deviance & $\mathrm{h}^{2}$ & Mean & CVe (\%) \\
\hline RL & $543.14^{* *}$ & 0.49 & 23.92 & 27.04 & $494.19^{* *}$ & 0.75 & 27.32 & 16.00 \\
\hline RSA & $837.92^{* *}$ & 0.42 & 145.89 & 18.90 & $800.39^{* *}$ & 0.73 & 177.97 & 10.87 \\
\hline RV & $55.87^{* *}$ & 0.12 & 4.89 & 15.00 & $45.59^{* *}$ & 0.32 & 6.32 & 10.13 \\
\hline RL1 & $1063.89^{* *}$ & 0.48 & 196.60 & 40.49 & $1007.30^{* *}$ & 0.71 & 230.21 & 23.05 \\
\hline RSA1 & $677.83^{* *}$ & 0.50 & 31.12 & 39.49 & $654.00^{* *}$ & 0.67 & 39.22 & 25.42 \\
\hline SDW & $638.79^{* *}$ & 0.56 & 38.78 & 25.53 & $668.25^{* *}$ & 0.68 & 48.99 & 21.76 \\
\hline RDW & $457.72^{* *}$ & 0.47 & 22.76 & 19.01 & $482.47^{* *}$ & 0.61 & 25.49 & 17.85 \\
\hline TDW & $696.93^{* *}$ & 0.56 & 61.53 & 21.22 & $716.57^{* *}$ & 0.72 & 74.47 & 17.53 \\
\hline SPC & $234.23^{* *}$ & 0.47 & 0.47 & 26.42 & $93.10^{* *}$ & 0.62 & 0.96 & 30.85 \\
\hline RPC & $302.83^{* *}$ & 0.27 & 0.22 & 54.59 & $102.11^{* *}$ & 0.49 & 0.34 & 32.43 \\
\hline
\end{tabular}

${ }^{a} \mathrm{RL}=$ total root length; $\mathrm{RSA}=$ root surface area; $\mathrm{RV}=$ root volume; $\mathrm{RL} 1=$ root $0-1-\mathrm{mm}$ diameter length; RSA1 = root 0-1 mm diameter surface area; SDW = shoot dry weight; RDW = root dry weight; TDW = total dry weight; $\mathrm{SPC}=$ shoot phosphorus content; $\mathrm{RPC}=$ root phosphorus content. $* *$ Significant at $0.01 \%$ probability.

Table 2. Genotypic correlation among traits related to phosphorus $(\mathrm{P})$ use efficiency evaluated in 35 inbred popcorn lines and two inbred maize lines (controls) under two P levels.

\begin{tabular}{|c|c|c|c|c|c|c|c|c|c|}
\hline Traitsa $^{\mathrm{a}}$ & RL & RSA & $\mathrm{RV}$ & RL1 & RSA1 & SDW & RDW & TDW & SPC \\
\hline \multicolumn{10}{|l|}{ LP } \\
\hline RSA & $0.97 * *$ & & & & & & & & \\
\hline RV & $0.57 * *$ & $0.71^{* *}$ & & & & & & & \\
\hline RL1 & $0.98^{* *}$ & $0.93 * *$ & $0.49^{* *}$ & & & & & & \\
\hline RSA1 & $0.96^{* *}$ & $0.92^{* *}$ & $0.47^{* *}$ & $0.98^{* *}$ & & & & & \\
\hline SDW & $0.89^{* *}$ & $0.89^{* * *}$ & $0.58^{* *}$ & $0.86^{* * *}$ & $0.84 * *$ & & & & \\
\hline RDW & $0.76^{* * *}$ & $0.79 * *$ & $0.62^{* *}$ & $0.69^{* *}$ & $0.69^{* *}$ & $0.79 * *$ & & & \\
\hline TDW & $0.88^{* *}$ & $0.89^{* *}$ & $0.60^{* *}$ & $0.85^{* *}$ & $0.84 * *$ & $0.98^{* *}$ & $0.87^{* *}$ & & \\
\hline SPC & 0.16 & 0.16 & 0.11 & 0.13 & 0.17 & 0.23 & 0.16 & 0.2 & \\
\hline RPC & 0.19 & 0.23 & 0.21 & 0.18 & 0.22 & $0.37^{*}$ & 0.17 & 0.32 & $0.60^{* *}$ \\
\hline \multicolumn{10}{|l|}{ HP } \\
\hline RSA & $0.97 * *$ & & & & & & & & \\
\hline $\mathrm{RV}$ & $0.69^{* *}$ & $0.80^{* * *}$ & & & & & & & \\
\hline RL1 & $0.97 * *$ & $0.91^{* *}$ & $0.56^{* *}$ & & & & & & \\
\hline RSA1 & $0.96^{* * *}$ & $0.92 * *$ & $0.57^{* * *}$ & $0.98^{* *}$ & & & & & \\
\hline SDW & $0.85^{* *}$ & $0.88^{* * *}$ & $0.75^{* *}$ & $0.78^{* *}$ & $0.75^{* *}$ & & & & \\
\hline RDW & $0.76^{* *}$ & $0.82^{* *}$ & $0.74^{* * *}$ & $0.72 * *$ & $0.69^{* *}$ & $0.86^{* *}$ & & & \\
\hline TDW & $0.85^{* *}$ & $0.89^{* * *}$ & $0.76^{* * *}$ & $0.79 * *$ & $0.77 * *$ & $0.98^{* *}$ & $0.91^{* *}$ & & \\
\hline SPC & $0.80^{* *}$ & $0.81^{* *}$ & $0.65^{* *}$ & $0.72 * *$ & $0.71^{* *}$ & $0.86^{* *}$ & $0.74^{* *}$ & $0.85^{* *}$ & \\
\hline RPC & 0.19 & 0.24 & 0.22 & 0.22 & 0.22 & 0.26 & $0.51^{* *}$ & $0.34^{*}$ & 0.32 \\
\hline
\end{tabular}

${ }^{\mathrm{a}} \mathrm{RL}=$ total root length; $\mathrm{RSA}=$ root surface area; $\mathrm{RV}=$ root volume; $\mathrm{RL} 1=$ root $0-1-\mathrm{mm}$ diameter length; RSA1 = root $0-1 \mathrm{~mm}$ diameter surface area; SDW = shoot dry weight; RDW = root dry weight; TDW = total dry weight; $\mathrm{SPC}=$ shoot phosphorus content; RPC $=$ root phosphorus content. $* * * *$ Significant at 0.01 and $0.05 \%$ probability, respectively.

Three clusters were also observed under HP conditions, with the first group (Pop 1 and 26) presenting high values for most of the variables; the second group (Pop 13, 07, 33, 02, 14, 30, $15,17,28,12,34,31,18$, and 32) presenting high values for DG, RSA, RV, R1DL, and R1DSA, and low values for RPC, and RDW; and a third group classified as unresponsive to P application.

PCA using all 35 lines and 10 traits revealed a difference in the distribution of lines on the plot and showed a higher distribution of lines in LP than in HP, indicating that the popcorn lines can be better distinguished under conditions of stress. The first component explained 
68.33 and $69.88 \%$ while the second component explained 17.30 and $18.04 \%$ of the total variance for LP and HP, respectively (Figure 2).
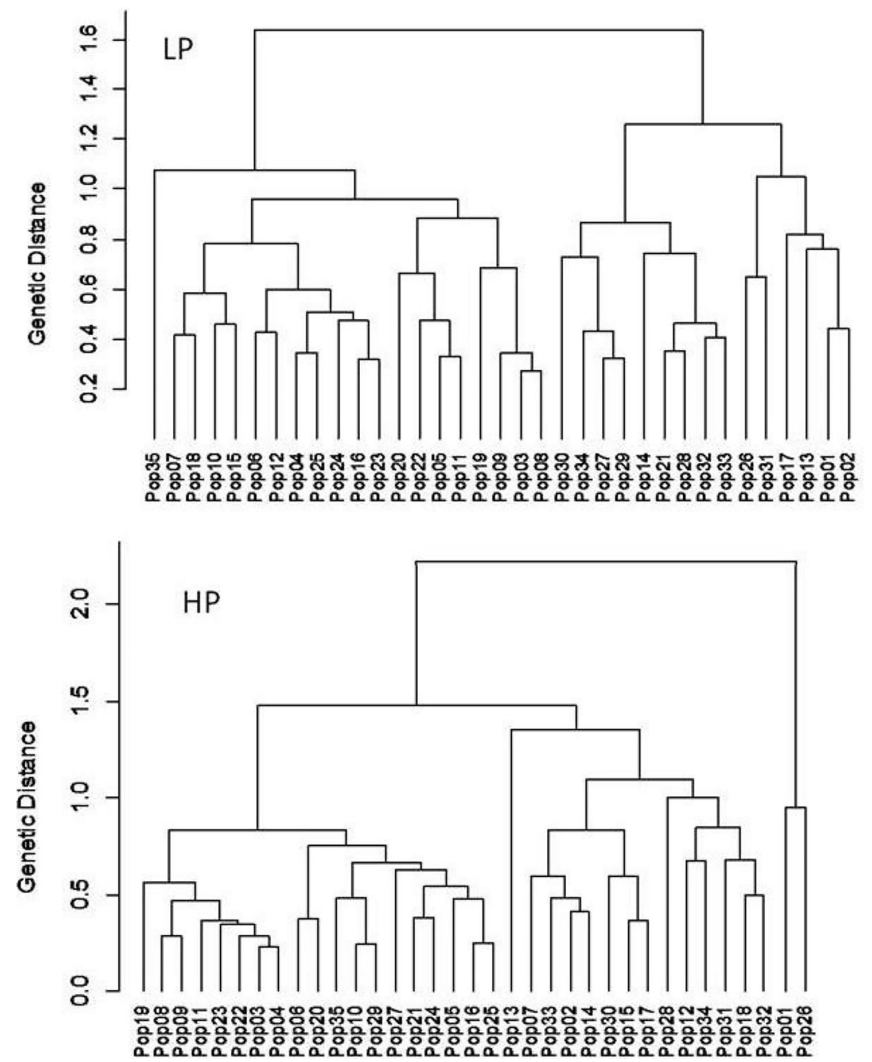

Figure 1. UPGMA dendrogram showing the genetic relationships of 35 inbred popcorn lines under two P levels.
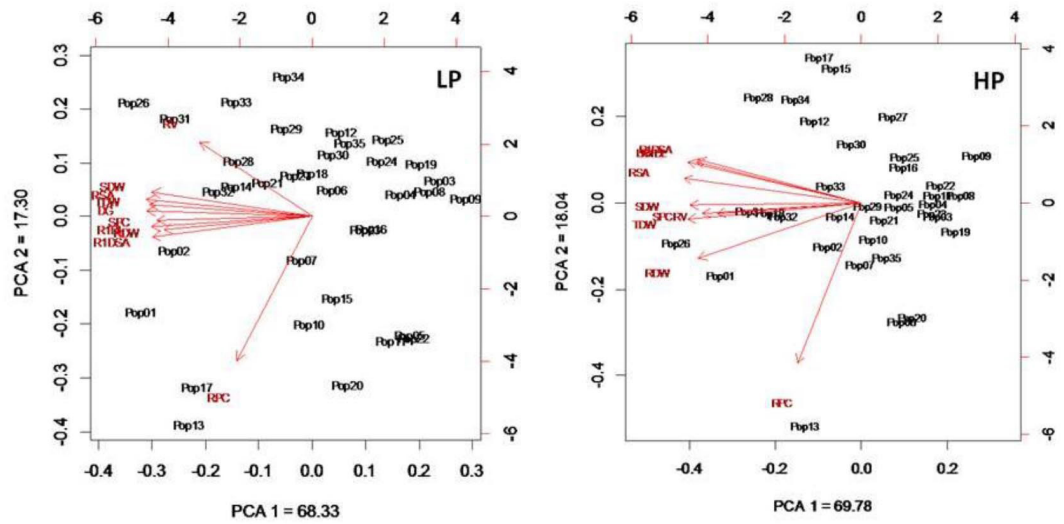

Figure 2. Principal component analysis (PCA) of the genetic relationships among 35 inbred popcorn lines and two inbred maize lines (controls) under two $\mathrm{P}$ levels. 
The selection index was consistent with the UPGMA clustering and PCA analyses in LP, and Pop1, 2, 13, 17, 26, and 31 were classified as tolerant to LP (Figure 3). The major characteristics of these lines include a smaller decrease in biomass production of the shoots and roots, higher values for root growth and architecture, and increased $\mathrm{P}$ absorption and transport.

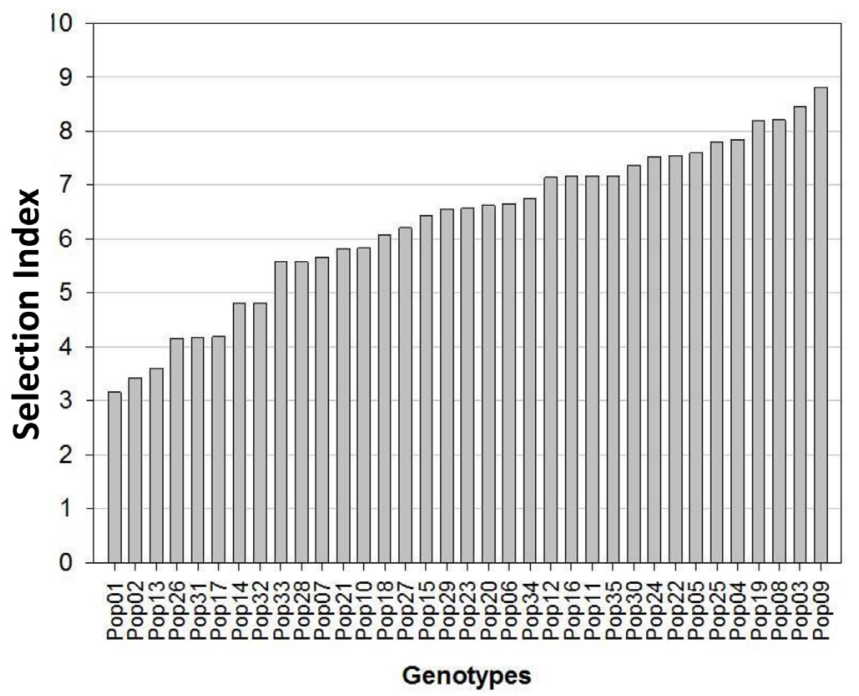

Figure 3. The mean values for 5 traits in popcorn maize under low $\mathrm{P}$ conditions based on the selection index.

\section{DISCUSSION}

The results of the present study showed that the average values for all variables were lower under LP, indicating that this condition affected the morphology and physiology of the plant. The heritability values observed for LP allow the use of TDW and SDW as indicators for germplasm selection for tolerance to LP levels. The values observed here are lower than those observed by Zhang et al. (2014), who analyzed 456 lines of maize in a nutrient solution containing two levels of $\mathrm{P}(0$ and $1000 \mu \mathrm{M})$ and found high heritability in lines grown without $\mathrm{P}$, with values ranging from 0.73 to 0.89 , and lower heritability in the presence of $\mathrm{P}$, with values ranging from 0.52 to 0.78 . When 32 tropical maize lines were analyzed in a nutrient solution containing 2.5 and $250 \mu \mathrm{M}$ P, the heritability values for RL, RV, and RSA were $0.93,0.81$, and 0.89 , respectively (de Sousa et al., 2012). A segregating population composed of 145 maize recombinant inbred lines (RILs) derived from a bi-parental cross of lines L3 (P-efficient) and L22 (P-inefficient) also showed high heritability values for these traits in maize seedlings grown under the same conditions (Azevedo et al., 2015).

Results of Pearson correlation were consistent with those obtained in other maize studies (Mundim et al., 2013; Zhang et al., 2014; Azevedo et al., 2015), in which morphological root and shoot traits were shown to be correlated. The positive correlation between biomass (TDW and SDW) and root measurements (DG, RSA, RL1, RSA1) is consistent with results from other studies, and indicates that if selection is performed according to such correlations, then genotypes with the highest values for these factors can be selected and high tolerance to P deficiency can be obtained (Bayuelo-Jiménez et al., 2011; Zhang et al., 2014). 
The observed variability clustered by UPGMA analysis may have been caused by the origin and breeding of each popcorn line, because this information is important for the breeder when determining optimal crosses. Thus, the most divergent and efficient lines can be used as founders to generate improved populations with a high frequency of genes favorable to traits involved in PUE. Moreover, efficient lines can be crossed with inefficient lines in order to generate segregating populations for quantitative trait loci mapping (Mundim et al., 2013), as was performed in several studies (Zhu and Lynch, 2004; Zhu et al., 2005; Hufnagel et al., 2014; Azevedo et al. 2015).

The PCA results were consistent with observations from the UPGMA clustering analysis, in which three clusters were found for both LP (efficient, intermediate, and inefficient) and HP. Under LP, lines Pop17 and 13 were highly correlated with the variable RPC and classified as highly efficient for P absorption, whereas for HP, only Pop13 was correlated, and this was considered to be responsive to $\mathrm{P}$ adsorption.

The lines classified as tolerant to LP by the selection index are promising candidates for future breeding programs for the generation of tolerance to LP in popcorn. Our results showed that it is possible to improve the accuracy and speed of selection for genotypes tolerant to LP. Early seedling phenotyping for P efficiency can accelerate a breeding program if the number genotypes that can be screened in a shorter period of time can be enhanced, and also raises the possibility of performing experiments throughout the year, including in seasons that are unfavorable for field studies (Mundim et al., 2013; Zhang et al., 2014). Magalhães et al. (2011) used the same selection method in maize lines and showed that it provided important information for the selection of genotypes tolerant to LP, thus improving the accuracy and speed of genotype selection.

\section{ACKNOWLEDGMENTS}

Research supported by the National Council of Scientific and Technological Development $(\mathrm{CNPq})$ and the Araucária Foundation of Paraná State.

\section{REFERENCES}

Amaral Jr AT, Gonçalves LSA, Freitas SP, Junior., Candido LS, et al. (2013). UENF 14: a new popcorn cultivar. Crop Breed. Appl. Biotechnol. 13: 218-220.

Azevedo GC, Cheavegatti-Gianotto A, Negri BF, Hufnagel B, et al. (2015). Multiple interval QTL mapping and searching for PSTOL1 homologs associated with root morphology, biomass accumulation and phosphorus content in maize seedlings under low-P. BMC Plant Biol. 15: 172. http://dx.doi.org/10.1186/s12870-015-0561-y

Bayuelo-Jiménez JS, Gallardo-Valdéz M, Pérez-Decelis VA, Magdaleno-Armas L, et al. (2011). Genotypic variation for root traits of maize (Zea mays L.) from the Purhepecha Plateau under contrasting phosphorus availability. F. Crop. Res. 121: 350-362. http://dx.doi.org/10.1016/j.fcr.2011.01.001

Bennetzen JL and Hake SC (2009). Handbook of maize: its biology. Springer Science, New York.

Calderón-Vázquez C, Sawers RJH and Herrera-Estrella L (2011). Phosphate deprivation in maize: genetics and genomics. Plant Physiol. 156: 1067-1077.http://dx.doi.org/10.1104/pp.111.174987

Cordell D, Drangert JO and White S (2009). The story of phosphorus: Global food security and food for thought. Glob. Environ. Change 19: 292-305. http://dx.doi.org/10.1016/j.gloenvcha.2008.10.009

de Sousa SM, Clark RT, Mendes FF, Oliveira AC, et al. (2012). A role for root morphology and related candidate genes in P acquisition efficiency in maize. Funct. Plant Biol. 39: 925-935. http://dx.doi.org/10.1071/FP12022

Elser JJ (2012). Phosphorus: a limiting nutrient for humanity? Curr. Opin. Biotechnol. 23: 833-838. http://dx.doi. org/10.1016/j.copbio.2012.03.001

Gonçalves LSA, Simôes L, Freitas SDP, Junior., Amaral AT, Junior., et al. (2014). Estimating combining ability in popcorn lines using multivariate analysis. Chil. J. Agric. Res. 74: 10-15. http://dx.doi.org/10.4067/S0718$\underline{58392014000100002}$ 
Hammond JP, Broadley MR and White PJ (2004). Genetic responses to phosphorus deficiency. Ann. Bot. (Lond.) 94: 323332. http://dx.doi.org/10.1093/aob/mch156

Hufnagel B, de Sousa SM, Assis L, Guimaraes CT, et al. (2014). Duplicate and conquer: multiple homologs of PHOSPHORUS-STARVATION TOLERANCE1 enhance phosphorus acquisition and sorghum performance on low-phosphorus soils. Plant Physiol. 166: 659-677.http://dx.doi.org/10.1104/pp.114.243949

Kumar B, Abdel-Ghani AH, Reyes-Matamoros J, Hochholdinger F, et al. (2012). Genotypic variation for root architecture traits in seedlings of maize (Zea mays L.) inbred lines. Plant Breed. 131: 465-478. http://dx.doi.org/10.1111/j.14390523.2012.01980.x

López-Arredondo DL, Leyva-González MA, González-Morales SI, López-Bucio J, et al. (2014). Phosphate nutrition: improving low-phosphate tolerance in crops. Annu. Rev. Plant Biol. 65: 95-123. http://dx.doi.org/10.1146/annurevarplant-050213-035949

Lynch JP and Brown KM (2012). New roots for agriculture: exploiting the root phenome. Philos. Trans. R. Soc. Lond. B Biol. Sci. 367: 1598-1604. http://dx.doi.org/10.1098/rstb.2011.0243

Magalhães PC, Souza TC and Cantão FRO (2011). Early evaluation of root morphology of maize genotypes under phosphorus deficiency. Plant Soil Environ. 57: 135-138.

Magnavaca R, Gardner CO and Clark RB (1987). Evaluation of maize inbred lines for aluminum tolerance in nutrient solution. In: Genetic aspects of plant mineral nutrition (Gabelman HW and Longhman BC, eds.). Martinus Nijhoff Publishers, Dordrecht, 255-65.

Moll RH, Kamprath EJ and Jackson WA (1982). Analysis and interpretation of factors, which contribute to efficiency of nitrogen utilization. Agron. J. 74: 562-564. http://dx.doi.org/10.2134/agronj1982.00021962007400030037x

Moterle LM, Braccini ALE, Scapim CA, Pinto RJB, et al. (2012). Combining ability of popcorn lines for seed quality and agronomic traits. Euphytica 185: 337-347. http://dx.doi.org/10.1007/s10681-011-0458-2

Mundim GB, Viana JMS and Maia C (2013). Early evaluation of popcorn inbred lines for phosphorus use efficiency. Plant Breed. 132: 613-619. http://dx.doi.org/10.1111/pbr.12119

Parentoni SN and Souza Júnior CL (2008). Phosphorus acquisition and internal utilization efficiency in tropical maize genotypes. Pesquisa Agropecu. Bras. 43: 893-901. http://dx.doi.org/10.1590/S0100-204X2008000700014

Pradhan S and Pokhrel MR (2013). Spectrophotometric determination of phosphate in sugarcane juice, fertilizer, detergent and water. Sci. World 11: 58-62. http://dx.doi.org/10.3126/sw.v11i11.9139

Resende MDV (2007). Genética biométrica e estatística no melhoramento de plantas perene. Editora Embrapa-SCT, Brasilia.

Richardson AE, Lynch JP, Ryan PR, Delhaize E, et al. (2011). Plant and microbial strategies to improve the phosphorus efficiency of agriculture. Plant Soil 349: 121-156. http://dx.doi.org/10.1007/s11104-011-0950-4

Rose TJ, Liu L and Wissuwa M (2013). Improving phosphorus efficiency in cereal crops: Is breeding for reduced grain phosphorus concentration part of the solution? Front. Plant Sci. 4: 444. PubMed http://dx.doi.org/10.3389/ fpls.2013.00444

Santos LS, Silva LS and Griebeler G (2014). Ácido ascórbico como agente redutor para determinação de fósforo por colorimetria. Cienc. Rural 44: 1015-1018. http://dx.doi.org/10.1590/S0103-84782014000600010

Schachtman DP, Reid RJ and Ayling SM (1998). Phosphorus uptake by plants: from soil to cell. Plant Physiol. 116: 447453.http://dx.doi.org/10.1104/pp.116.2.447

Scholz RW, Ulrich AE, Eilittä M and Roy A (2013). Sustainable use of phosphorus: a finite resource. Sci. Total Environ. 461-462: 799-803.http://dx.doi.org/10.1016/j.scitotenv.2013.05.043

Suh S and Yee S (2011). Phosphorus use-efficiency of agriculture and food system in the US. Chemosphere 84: 806-813.

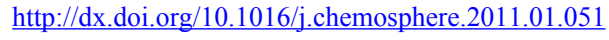

Veneklaas EJ, Lambers H, Bragg J, Finnegan PM, et al. (2012). Opportunities for improving phosphorus-use efficiency in crop plants. New Phytol. 195: 306-320. http://dx.doi.org/10.1111/j.1469-8137.2012.04190.x

Walker V, Couillerot O, Felten A, Bellvert F, et al. (2011). Variation of secondary metabolite levels in maize seedling roots induced by inoculation with Azospirillum, Pseudomonas and Glomus consortium under field conditions. Plant Soil $\cdots$ : 151-163.

Wang X, Shen J and Liao H (2010). Acquisition or utilization, which is more critical for enhancing phosphorus efficiency in modern crops? Plant Sci. 179: 302-306. http://dx.doi.org/10.1016/j.plantsci.2010.06.007

Zhang L, Li J, Rong T, Gao S, et al. (2014). Large-scale screening maize germplasm for low-phosphorus tolerance using multiple selection criteria. Euphytica 197: 435-446. http://dx.doi.org/10.1007/s10681-014-1079-3

Zhu J and Lynch JP (2004). The contribution of lateral rooting to phosphorus acquisition efficiency in maize (Zea mays) seedlings. Funct. Plant Biol. 31: 949. http://dx.doi.org/10.1071/FP04046

Zhu J, Kaeppler SM and Lynch JP (2005). Mapping of QTL controlling root hair length in maize (Zea mays L.) under phosphorus deficiency. Plant Soil 270: 299-310. http://dx.doi.org/10.1007/s11104-004-1697-y 